Pesq. Vet. Bras. 37(12):1545-1553, dezembro 2017 DOI: $10.1590 / \mathrm{S} 0100-736 \mathrm{X} 2017001200030$

\title{
Padronização da quantificação do fator de crescimento semelhante à insulina I (IGF-I) em plasma bovino por ELISA ${ }^{1}$
}

\author{
Marcos Antonio Maioli ${ }^{2 *}$ Guilherme de Paula Nogueira²
}

\begin{abstract}
Maioli M.A. \& Nogueira G.P. 2017. [Standardization of ELISA for the measurement of Insulin-Like Growth Factor I (IGF-I) in bovine plasm.] Padronização da quantificação do fator de crescimento semelhante a insulina I (IGF-I) em plasma bovino por ELISA. Pesquisa Veterinária Brasileira 37(12):1545-1553. Departamento de Apoio a Produção e Saúde Animal, Faculdade de Medicina Veterinária de Araçatuba, Universidade Estadual Paulista, Unesp-Araçatuba, Rua Clóvis Pestana 793, Araçatuba, SP 16050-680, Brazil. E-mail: maioli_marcos@hotmail.com

This study aimed to standardize an in house competitive enzyme-linked immunosorbent assay (cELISA) to determine plasma concentrations of total insulin-like growth factor I (IGF-I) for the bovine specie using the amplification biotin-streptavidin peroxidase system. The IGF-I was extracted from insulin-like growth factor binding proteins (IGFBPs) using the acidified glycine buffer followed by the $\mathrm{pH}$ neutralization with sodium hydroxide. The microplates were coated with anti-rabbit IgG, thereafter the measurements were carried out using two approaches, one with a prior incubation of samples with the anti-h-IGF-I antibody and another without previous incubation (simultaneous addition of IGF-I and biotinylated sample). The best results were obtained using the method without the prior incubation, using the following combination of reagents: microplates were coated with $0.25 \mu \mathrm{g} / \mathrm{well}$ of anti-rabbit IgG, the specific antibody at a dilution of 1:250,000 and $0.06 \mathrm{ng} /$ well of biotinylated IGF-I. The in house methodology showed sensitivity of $50 \mathrm{ng} / \mathrm{ml}$, a correlation between doses of 0.945 when compared to a commercial method. In addition, after 33 assays (quantification of 1114 samples) the proposed methodology presented a good precision, with inter-assay variation coefficients of $12.94 \%$ and $20.71 \%$ for the high and low controls, respectively. Finally, we concluded that ELISA method for the quantification of total IGF-I using the system biotin-streptavidin-peroxidase amplification in a competitive assay is established and is presented as a useful tool for studies aimed at monitoring the IGF-I concentrations.
\end{abstract}

INDEX TERMS: Insulin-like growth factor I, IGF-I, plasm, bovine, ELISA, hormone, validation.

RESUMO.- Esse estudo teve como objetivo a padronização de um ensaio imunoenzimático competitivo (cELISA) in house para a determinação das concentrações plasmáticas do fator de crescimento semelhante a insulina I (IGF-I) total para a espécie bovina, utilizando o sistema de amplificação biotina-estreptavidina peroxidase. O IGF-I foi extraído das proteínas ligadoras do fator de crescimento semelhante a insulina I (IGFBP), utilizando o tampão glicina acidificado seguido de neutralização do pH com hidróxido de sódio. As

\footnotetext{
${ }^{1}$ Recebido em 29 de janeiro de 2016.

Aceito para publicação em 11 de abril de 2017

${ }^{2}$ Departamento de Apoio a Produção e Saúde Animal, Faculdade de Medicina Veterinária, Universidade Estadual Paulista Júlio de Mesquita Filho (Unesp), Rua Clóvis Pestana 793, Dona Amélia, Araçatuba, SP 16050680, Brasil. E-mail: gpn@fmva.unesp.br, *Autor para correspondência: maioli_marcos@hotmail.com
}

microplacas foram sensibilizadas com anti IgG de coelho, e as dosagens realizadas utilizando duas abordagens, um método com incubação prévia das amostras com o anticorpo anti-h-IGF-I e outro sem incubação prévia (adição simultânea de IGF-I biotilinado e amostra). Os melhores resultados foram obtidos utilizando o método sem incubação prévia, com a sensibilização da placa com $0,25 \mu \mathrm{g} /$ poço de anti-IgG de coelho, o anticorpo específico na diluição 1:250.000 e $0,06 \mathrm{ng} /$ poço de IGF-I biotinilado. 0 ensaio in house apresentou um limite inferior de detecção de $50 \mathrm{ng} / \mathrm{mL}$, uma correlação de 0,945 entre doses quando comparado a uma metodologia comercial. Os coeficientes de variação inter-ensaio de $12,94 \%(345,8 \mathrm{ng} / \mathrm{mL})$ para os controles alto e $20,71 \%(131,6 \mathrm{ng} / \mathrm{mL})$ para o baixo. Dessa forma, conclui-se que a metodologia imunoenzimática para quantificação de IGF-I total utilizando o sistema de amplificação biotina- 
-estreptavidina peroxidase em um ensaio competitivo está estabelecida e apresenta-se como uma ferramenta útil para estudos que visem o monitoramento das concentrações de IGF-I.

TERMOS DE INDEXAÇÃO: Fator de crescimento, insulina I, IGF-I, plasma, bovino, ELISA, hormônio, validação.

\section{INTRODUÇÃO}

$\mathrm{O}$ fator de crescimento semelhante à insulina I (IGF-I), ou somatomedina C, é um peptídeo com peso molecular de aproximadamente $7,6 \mathrm{kDa}$ composto por 70 aminoácidos pertencente à superfamília da insulina, devido a sua relação estrutural com a pró-insulina (Andoh 2005). É um potente mitógeno sintetizado por diversos órgãos, principalmente pelo fígado, em resposta ao hormônio de crescimento produzido pela hipófise (Yakar et al. 1999) e que atua como mediador metabólico relacionado com o início da puberdade em novilhas (Radcliff et al. 2004, Beltran 2007).

A atividade estimulatória sobre os processos reprodutivos desempenhada pelo IGF-I ocorre de duas maneiras, uma por ação local nos ovários estimulando o crescimento folicular que deriva em maior produção de estradiol com consequente liberação de picos do hormônio luteinizante (Simpson et al. 1991) e outra por ação direta no hipotálamo induzindo a liberação de kisspeptina que é um importante neurotransmissor estimulatório da secreção do hormônio liberador de gonadotrofinas (Hiney et al. 2010).

0 peso e a condição corporal, durante o período pré-puberal, são fatores determinantes para a primeira ovulação (Garcia et al. 2002) e apresentam correlação de 0,88 a 0,92 com as concentrações circulantes de IGF-I (Lacau-Mengido et al. 2000). Além da associação com os processos reprodutivos, a concentração periférica de IGF-I pode também ser utilizada como um parâmetro indicador do status nutricional (Ketelslegers et al. 1995).

Contudo, mesmo perante a reconhecida importância fisiológica desse hormônio sobre os aspectos produtivos e reprodutivos, as metodologias disponíveis para dosagem de IGF-I em sua grande maioria não foram corretamente validadas para a espécie bovina e apresentam um elevado custo, limitando o estudo desse hormônio em pesquisas desenvolvidas com elevado número de animais. Sendo assim, o objetivo dessa pesquisa consistiu na padronização um ensaio imunoenzimático competitivo (cELISA) para a determinação das concentrações plasmáticas de IGF-I total para a espécie bovina, utilizando o sistema de amplificação biotina-estreptavidina peroxidase.

\section{MATERIAL E MÉTODOS}

\section{Preparação do IGF-I conjugado com biotina}

Para a conjugação, a biotina utilizada foi o éster do ácido biotinamidohexanóico $\mathrm{N}$-hidroxisuccinimídico (Biotinamidohexanoic acid N-hydroxysuccinimide ester, Sigma-Aldrich, cod. B2643) e o hormônio h-IGF-I (Sigma-Aldrich, cod. I3769). Inicialmente, foi preparada uma solução de biotina $1 \mathrm{mg} / \mathrm{mL}$ em dimetilsulfóxido (DMSO) e $25 \mu \mathrm{g}$ de IGF-I foram solubilizados em $200 \mu \mathrm{L}$ de PBS (50mM NaPO e $\mathrm{NaCl} 150 \mathrm{mM}$ ) pH=7,4. Em seguida, em um frasco protegido da luz, $29,6 \mu \mathrm{L}$ da solução de biotina foram misturados com $200 \mu \mathrm{L}$ da solução contendo o hormônio, sendo respeitada a razão de 20mol de biotina para cada mol de hormônio (20:1, mol/ mol) e foi realizada uma incubação por 3 horas à temperatura ambiente sob agitação constante.

Ao final da incubação, a conjugação foi interrompida com $20 \mu \mathrm{L}$ de $\mathrm{NH}_{4} \mathrm{Cl} 1 \mathrm{M}$ por $30 \mathrm{~min}$ à temperatura ambiente. Posteriormente, ao conjugado foram adicionados $2 \mathrm{~mL}$ de PBS acrescido de BSA $1 \%$.

A biotina livre e o excesso de sais foram removidos por filtração, utilizando uma coluna de dessalinização (Vivaspin 2, GE Healthcare, cod. 28-9322-40) com filtro de 3kDa. Foram realizadas 3 centrifugações a 3000 x g por 50 minutos a $4^{\circ} \mathrm{C}$, e a cada centrifugação, o volume do filtrado no interior da coluna era reposto pela adição do mesmo volume de PBS (50 $\mathrm{mM} \mathrm{NaPO}_{4}$ e $\left.\mathrm{NaCl} 150 \mathrm{mM}\right)$ $\mathrm{pH}=7,4$. Por fim, ao hormônio biotinilado foi adicionado glicerol na proporção $1: 1(\mathrm{v} / \mathrm{v})$, e este aliquotado e estocado a $-20^{\circ} \mathrm{C}$.

Para posterior utilização nos ensaios, o antígeno conjugado teve sua concentração estimada levando-se em consideração a massa de IGF-I utilizada $(25 \mu \mathrm{g})$ e o volume final obtido $(2,9 \mathrm{~mL})$, sendo a concentração estimada de $8,62 \mu \mathrm{g} / \mathrm{mL}$

\section{Extração para quantificação de IGF-I total}

0 método adotado para extração das amostras, ou seja, desligamento do IGF-I das proteínas ligadoras do fator de crescimento semelhante à insulina I (IGFBP) foi o mesmo descrito por Lalman et al. (2000). Em tubos de polipropileno $12 \times 75 \mathrm{~mm}$ foram adicionados $460 \mu \mathrm{L}$ de tampão de ensaio, composto por $120 \mathrm{mM} \mathrm{de} \mathrm{NaCl}$, $20 \mathrm{mM} \mathrm{Na}_{2} \mathrm{HPO}_{4}, 10 \mathrm{mM}$ de EDTA, 0,05\% de Tween 20, 0,02\% de sulfato de protamina e gelatina $1 \%, \mathrm{pH}=7,3,10 \mu \mathrm{L}$ de amostra e $400 \mu \mathrm{L}$ de tampão glicina $1 \mathrm{M} \mathrm{pH=3,2}$. Os tubos foram tampados, o conteúdo homogeneizado em vórtex multitubos (VWR, modelo VX-2500) e incubados por 48 horas a $37^{\circ} \mathrm{C}$. Após esse período de incubação em meio ácido, o pH foi neutralizado pela adição de $130 \mu \mathrm{L}$ de $\mathrm{NaOH} 0,5 \mathrm{~N}$.

Nesse sistema de extração do IGF-I são utilizados $10 \mu \mathrm{L}$ de amostras que posteriormente são diluídos em $990 \mu \mathrm{L}$ de uma combinação de reagentes (tampão de ensaio, tampão glicina e $\mathrm{NaOH}$ ), resultando em um fator de diluição de 1:100 que será considerado na elaboração da curva padrão.

\section{Preparo das microplacas (sensibilização e bloqueio)}

Para sensibilização das microplacas de 96 poços (Nunc, Maxisorp, Thermo Scientific, cod. 80040LE0910) foi utilizada IgG de cabra anti-IgG de coelho (Sigma-Aldrich, cod. R2004). A cada poço foram adicionados $100 \mu \mathrm{L}$ de tampão carbonato $0,0522 \mathrm{M}, \mathrm{pH}=9,6$ contendo anti-IgG de coelho (em diferentes concentrações). Após incubação overnight a $4^{\circ} \mathrm{C}$, as placas foram lavadas com $300 \mu \mathrm{L} /$ poço de solução de Tween $800,05 \%$ por 2 vezes, utilizando lavadora de microplacas Thermo Scientific (cod. 5165000).

Posteriormente, foram realizados dois bloqueios dos sítios de ligação remanescentes nos poços, com a adição de $300 \mu \mathrm{L} /$ poço de PBS-BSA 1\%, pH=7,2. A cada bloqueio as placas foram incubadas a $37^{\circ} \mathrm{C}$ por 50 min e submetidas a duas lavagens com solução de Tween 80 0,05\%.

\section{Estabelecimento da curva padrão}

Para elaboração dos padrões foi utilizado o h-IGF-I recombinante (Sigma-Aldrich, cod. I3769) sendo considerado nesta etapa a diluição de 1:100 induzida pelo processo de extração. Dessa forma, foi eliminada a necessidade de correção da dose após a quantificação das amostras.

Foi preparada uma solução estoque com $12 \mathrm{ng} / \mathrm{mL}$, o equivalente a $1200 \mathrm{ng} / \mathrm{mL}$, e a partir dessa solução foram realizadas diluições seriadas para elaboração dos demais padrões. As concentrações utilizadas foram as equivalentes a 2,34; 4,68; 9,36; 
18,$75 ; 37,5 ; 75 ; 150 ; 300 ; 600 \mathrm{ng} / \mathrm{mL}$. Essa faixa de concentração foi escolhida por abranger as concentrações fisiológicas de IGF-I no soro de bovino como apresentado por Buratini et al. (2000) e Cooke et al. (2013).

Foram realizados testes com diferentes volumes da curva padrão (20; 40; 60 e $80 \mu \mathrm{L} /$ poço), com o intuito de identificar o mais adequado para o ensaio. Para isso, os dados foram plotados em gráficos, sendo que no eixo $\mathrm{X}$ foram inseridas as concentrações dos padrões convertidas em logaritmo de base 10 e no eixo Y foram inseridos os valores das densidades ópticas e aplicada a regressão logística de 4 parâmetros.

Os critérios adotados para escolha do volume foram: índice de correlação entre a densidade óptica obtida e as doses $\geq 0,9$ assim como os valores de IC50 (concentração efetiva do antígeno que provoca a redução de $50 \%$ da variação total da densidade óptica).

\section{Procedimentos adotados para estabelecimento do ensaio}

Testes de ligação. Previamente ao estabelecimento da curva padrão e quantificação de amostras, foram realizadas avaliações para encontrar a melhor combinação entre a concentração do anticorpo específico, anticorpo de captura e do antígeno marcado para utilização nos ensaios.

Foram testados dois protocolos experimentais: (i) após a sensibilização das microplacas com diferentes concentrações de anti-IgG de coelho $(0,25 ; 0,5 ; 0,75$ e $1 \mu \mathrm{g}$ IgG/poço), como descrito no item preparo das placas, foram adicionados $100 \mu \mathrm{L}$ de diferentes diluições de anticorpo anti-h-IGF-I (Hormone \& Pituitary Program, Harbor-UCLA Medical Centre, Carson, CA, USA, cod. AFP4892898) preparadas em tampão de ensaio, seguida pela adição de diferentes concentrações de IGF-I conjugado a biotina $(0,04 ; 0,08 ; 0,16 ; 0,32 \mathrm{ng} / 100 \mu \mathrm{L} /$ poço) diluído em tampão de ensaio, sendo então realizada uma incubação a $4^{\circ} \mathrm{C}$ por 4 horas; (ii) consiste nos mesmos passos descritos acima, contudo as diluições do anticorpo específico e do antígeno marcado foram ampliadas, assim como o tempo de incubação (24h). Em ambos os protocolos, durante esta etapa, não foram realizadas lavagens entre a adição do anticorpo específico e antígeno biotinilado.

Após a incubação com o antígeno marcado, em ambos os sistemas citados, foram realizadas duas lavagens com Tween 80 $0,05 \%$, com posterior adição de 2,5mU de peroxidase $100 \mu \mathrm{L} /$ poço (Streptavidin-POD conjugate $500 \mathrm{U} / \mathrm{mL}$, Roche). As microplacas foram protegidas da luz e incubadas por 30 minutos a $4^{\circ} \mathrm{C}$, uma vez que a peroxidase é sensível à luz. Ao término da incubação as placas foram submetidas a 3 lavagens com Tween 80 $0,05 \%$, e então foram adicionados $100 \mu \mathrm{L} /$ poço de substrato composto por 2mM 3,3',5,5'-Tetrametilbenzidina (TMB), $100 \mathrm{mM}$ de ácido cítrico, 10,63 mM de peróxido de ureia, 126,8mM de $\mathrm{Na}_{2} \mathrm{H}$ $\mathrm{PO}_{4}$ e $4 \%$ de DMSO.

As microplacas foram incubadas a $37^{\circ} \mathrm{C}$, protegidas da luz, por 40 minutos e a reação de oxidação do substrato pela enzima foi interrompida pela adição de $30 \mu \mathrm{L} /$ poço de ácido sulfúrico $2 \mathrm{M}$. A determinação da densidade óptica foi imediatamente realizada em leitor de microplacas (Sunrise, Tecan, cod. 16039400), utilizando o comprimento de onda de $450 \mathrm{~nm}$.

Ensaio para quantificação de IGF-I. Foram testados dois protocolos experimentais, sendo a principal variação entre os dois a existência ou não de uma pré-incubação entre as amostras e o anticorpo anti-IGF-I para posterior adição do antígeno marcado.

O primeiro protocolo, com incubação prévia, teve início com a sensibilização da microplaca com posterior bloqueio. Foram adicionados sequencialmente os padrões, amostras (nos poços referentes a ligação não específica, ligação máxima e branco foi adicionado tampão de ensaio) e $100 \mu \mathrm{L} /$ poço do anticorpo anti-IGF-I, seguida de incubação de 24 horas a $4^{\circ} \mathrm{C}$.
Posteriormente, as microplacas foram lavadas por duas vezes com solução de Tween 80 0,05\% e após a lavagem adicionou-se $100 \mu \mathrm{L} /$ poço do IGF-I biotinilado e uma nova incubação a $4^{\circ} \mathrm{C}$ por 4 horas foi realizada. Ao final desse período, foram realizadas duas lavagens com Tween 80 0,05\% e os passos posteriores (adição da peroxidase, substrato e leitura) foram os mesmos adotados nos testes de ligação.

No segundo protocolo, sem incubação prévia, após a sensibilização e bloqueio das placas, foram adicionados sequencialmente os padrões, amostras (nos poços referentes à ligação não específica, ligação máxima e branco foi adicionado tampão de ensaio), $100 \mu \mathrm{L} /$ poço do anticorpo anti-IGF-I e $100 \mu \mathrm{L} /$ poço do IGF-I biotinilado, não sendo realizadas incubações ou lavagens das microplacas entre as adições dos reagentes citados.

Após a inclusão dos reagentes acima citados foi realizada uma incubação de 24 horas a $4^{\circ} \mathrm{C}$, seguida por duas lavagens com Tween 80 0,05\%. Os passos subsequentes (adição da peroxidase, substrato e leitura) foram os mesmos realizados nos testes de ligação.

\section{Procedimentos de validação do método in house}

Exatidão e Precisão. A exatidão foi avaliada por meio da comparação das concentrações obtidas pelos diferentes protocolos in house de ELISA apresentados nesse estudo (com e sem incubação prévia das amostras com o anticorpo específico) e as obtidas, com as mesmas amostras, utilizando o kit comercial de ELISA adquirido da Anshlabs (cod. AL-121) para quantificação de IGF-I total, seguindo as instruções do fabricante.

Para isso, foram quantificadas 37 amostras de plasma coletadas de 3 novilhas da raça Nelore durante os 7 primeiros meses de vida em experimento realizado entre os anos de 2011 e 2013. A quantificação das amostras utilizando o kit comercial foi realizada em duplicata, já as quantificações das amostras com o método in house foram realizadas em dois ensaios independentes e em duplicata. As doses obtidas entre as duas metodologias foram correlacionadas e a diferença percentual calculada.

A avaliação da precisão do método in house foi realizada apenas no método sem incubação prévia. Em amostras de plasma, coletadas de vacas no quarto dia pós-parto, foram adicionados 350 e 100ng/mL de IGF-I e realizado o processo de extração para posterior quantificação.

O plasma descrito acima, utilizado como matriz de diluição, foi submetido a dosagem de IGF-I utilizando o kit fornecido pela Anshlabs e apresentou concentrações inferiores a faixa de detecção do kit $(7,5 \mathrm{ng} / \mathrm{mL})$, valores similares aos apresentados por Piechotta et al. (2014).

A principal razão do uso do plasma como diluente foi simular os efeitos da matriz de diluição, além disso para evitar que o IGF-I livre adicionado ficasse ligado às IGFBP presentes no plasma foi realizada a extração. Essas amostras enriquecidas foram utilizadas como controles alto e baixo e a precisão dos ensaios in house foi avaliada pelos coeficientes de variação das doses desses controles intra e inter-ensaio.

Sensibilidade e limite de quantificação inferior. A avaliação desses parâmetros foi realizada utilizando o teste de paralelismo, sendo que para o correto estabelecimento desses parâmetros foi levada em consideração a necessidade do processo de extração, por esse motivo a diluição sequencial foi realizada na amostra previamente a extração.

Para isso, uma amostra foi dosada utilizando o método in house sem ou com diluição sequencial, utilizando como diluente o tampão de ensaio (1:2, 1:4, 1:8, amostra/tampão). Essas amostras foram extraídas em duplicata e quantificadas em triplicata em 2 ensaios independentes. Os resultados foram comparados com a dose obtida com o kit e a dose estimada resultante das diluições subsequentes. 
Avaliação da linearidade do método. 0 estudo da linearidade do ELISA in house proposto, ou seja, a avaliação da linearidade da variação da densidade óptica, em reposta à inclusão de concentrações crescentes de IGF-I, foi feita nas 4 curvas padrão realizadas durante os ensaios de quantificação de IGF-I nos testes de aplicabilidade do método.

Os valores calculados pela equação resultante da conversão dos dados foram comparados com a concentração nominal dos padrões e os resíduos (diferença entre as doses nominais e as calculadas) plotados em gráficos para avaliação da dispersão.

Esses resultados foram comparados com os obtidos com a equação logística de 4 parâmetros (método não linear de cálculo das doses).

Análise estatística. 0 modelo estatístico utilizado para análise e elaboração da curva padrão foi a regressão logística de 4 parâmetros. Para avaliação da exatidão do método analítico, foi realizada a correlação de Pearson seguida pela regressão linear, nos testes de linearidade foram realizadas avaliações da distribuição de resíduos. 0 programa utilizado para os cálculos estatísticos foi o GraphPad Prism, versão 6.0 para Windows.

\section{RESULTADOS}

\section{Testes de ligação}

No teste de ligação com incubação de apenas 4 horas a combinação de diluições que resultou em uma densidade óptica próxima a 1,0 foi $0,25 \mu \mathrm{g}$ de IgG anti-coelho/poço, 0,08ng de IGF-I conjugado à biotina/poço e o anticorpo anti-IGF-I na diluição 1:80.000 (Fig.1A).

Para o teste de ligação com incubação de 24 horas (Fig.1B), foram obtidas densidades ópticas mais elevadas, por esse motivo além das concentrações testadas anteriormente foram testadas diluições maiores do an- ticorpo (1:160.000; $1: 200.000 ; 1: 250.000$ e $1: 300.000)$ e menores quantidades de IGF-I biotinilado $(0,04 ; 0,06$; 0,08 e $0,16 \mathrm{ng} /$ poço). Nesse caso, a combinação escolhida foi $0,25 \mu \mathrm{g}$ de anti- IgG de coelho/poço, 0,06 ng de IGF-I biotinilado/poço e o anticorpo anti-IGF-I nas diluições de 1:80.000 e 1:250.000 que resultaram em uma densidade óptica próxima a 2,0 .

\section{Curva padrão}

Inicialmente, foram elaboradas 11 soluções padrão de IGF-I com concentrações crescentes: 2,34; 4,68; 9,37; 18,$75 ; 37,5 ; 75 ; 150 ; 300 ; 600 ; 750$ e $1000 \mathrm{ng} / \mathrm{mL}$.

Na Figura 2A estão representados os resultados da variação do volume das soluções da curva padrão utilizando apenas o método com incubação prévia das amostras com o anticorpo anti-h-IGF-I. A utilização de 20 ou $40 \mu \mathrm{L}$ das soluções da curva padrão produziram diminuição na densidade óptica apenas a partir de 300 (2,47 unidades de log) e a $75 \mathrm{ng} / \mathrm{mL}$ (1,87 unidades de log), respectivamente.

Os melhores resultados foram obtidos com 60 e $80 \mu \mathrm{L}$, que promoveram redução na densidade óptica a partir de $18,75 \mathrm{ng} / \mathrm{mL}$, com coeficientes de correlação de $-0,9232$ e $-0,9528$ e $r^{2} 0,9978$ e 0,9905, respectivamente (Fig.2A). Todavia quando comparados os valores da soma de quadrados (SQ) e o desvio padrão dos resíduos (DPRes), o uso de $60 \mu \mathrm{L}$ das soluções padrão apresentou valores de 0,0075 e 0,0205 , sendo esses inferiores aos obtidos com o uso de $80 \mu \mathrm{L}(0,0354$ para DP e 0,0444 para DPRes). Outro aspecto avaliado foi o IC50, ou seja, a concentração que provoca a redução de $50 \%$ da variação total da densidade óptica
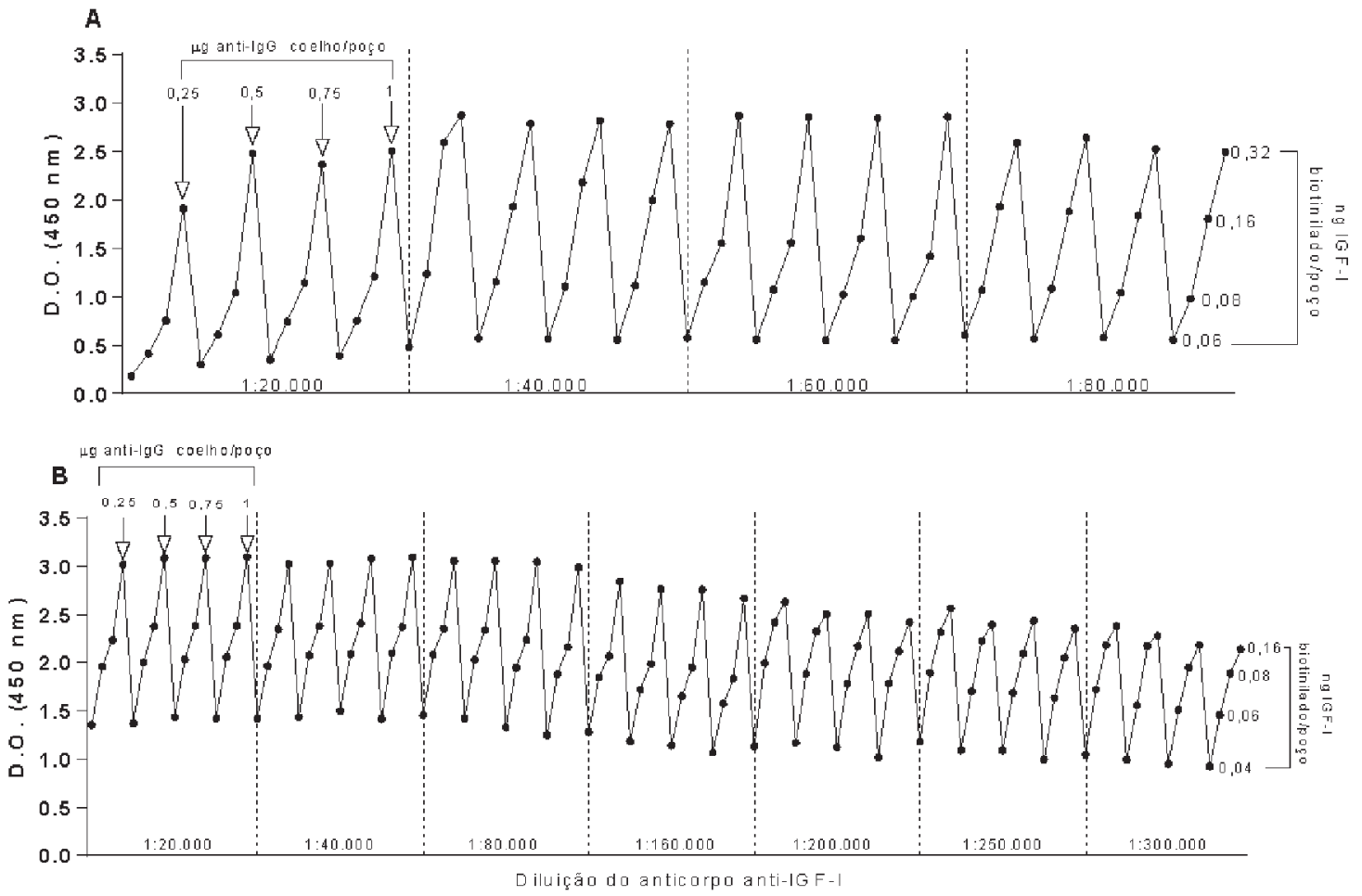

Fig.1. Testes de ligação realizados com incubação a $4^{\circ} \mathrm{C}$ por (A) 4 horas e (B) 24 horas. As setas indicam as diferentes concentrações de anti-IgG de coelho utilizadas para sensibilização dos poços e as linhas pontilhadas delimitam os intervalos das diluições do anticorpo anti-IGF-I. DO = densidade óptica. 

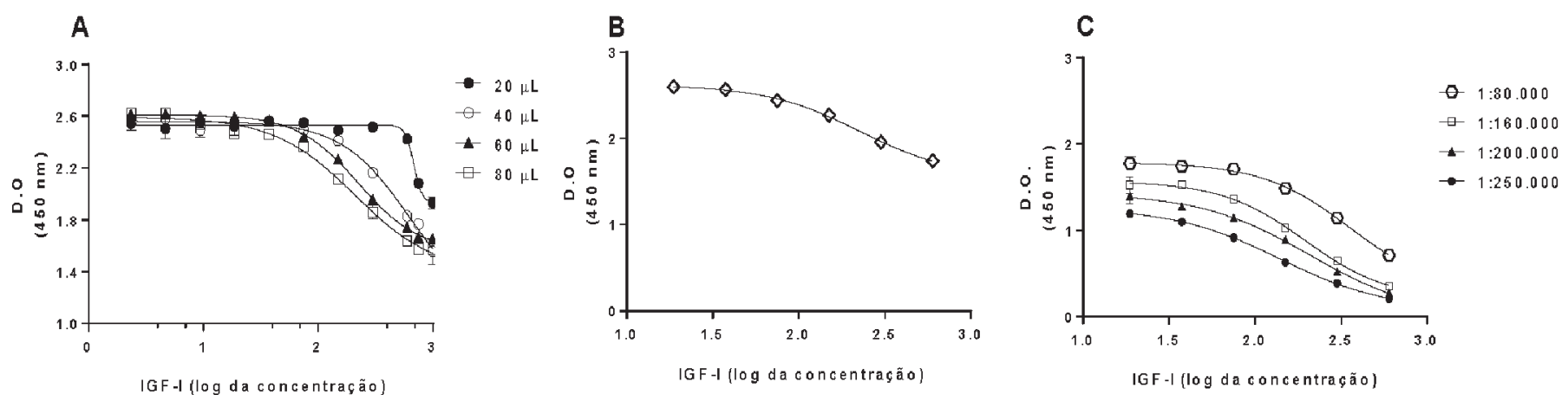

Fig.2. Curvas padrão usadas como referência para quantificação de IGF-I. (A) Variação nos volumes dos pontos da curva padrão utilizando o protocolo com incubação prévia. (B) Curva padrão em ensaio sem incubação prévia utilizando $60 \mu \mathrm{L}$ das soluções padrão e anticorpo anti-IGF-I na diluição 1:80.000. (C) Curva padrão em ensaio sem incubação prévia utilizando $60 \mu \mathrm{L}$ das soluções padrão com diferentes diluições de anticorpo anti-IGF-I. Os experimentos foram realizados em triplicata e os resultados apresentados como média \pm EPM.

obtida na curva padrão, e o uso de $60 \mu \mathrm{L}$ resultou em um IC50 de 224,1, superior ao obtido com $80 \mu \mathrm{L}(210,3)$ sendo assim escolhido como volume a ser utilizado para a realização dos ensaios.

Além do estabelecimento do volume da curva padrão, as soluções com concentrações equivalentes a 2,34; 4,68; 9,37; 750 e $1000 \mathrm{ng} / \mathrm{mL}$ foram retiradas da curva padrão em virtude da baixa variação na porcentagem de ligação $\left(\mathrm{B} / \mathrm{B}_{0}\right)$, inferior a 3\% (Fig.2A). Sendo assim, as concentrações dos pontos da curva padrão variaram entre 18,75 e $600 \mathrm{ng} / \mathrm{mL}$.

A partir desse ponto, as avaliações começaram a ser realizadas também com o protocolo sem incubação prévia, utilizando os mesmos parâmetros estabelecidos anteriormente (volume e concentração dos padrões), porém com diferentes diluições de anticorpo anti-IGF-I (1:80.000; $1: 160.000 ; 1: 200.000 ; 1: 250.000$ e $1: 300.000$ ).

Essa modificação resultou em redução na densidade óptica, sendo esta dependente do aumento da diluição do anticorpo anti-IGF-I, assim como na amplitude de variação da D.0. (Fig.2B,C). Os coeficientes de correlação e da regressão no método sem incubação prévia das amostras com o anticorpo específico apresentaram valores numericamente superiores ao método com incubação prévia, além disso houve uma redução nos valores da soma de quadrados, bem como do desvio padrão dos resíduos, principalmente nas diluições de anticorpo 1:250.000 e 1:300.000, e o IC50 dessas curvas apresentou valor similar (Quadro 1).

\section{Exatidão e precisão}

Com o intuito de avaliar a exatidão do ensaio 37 amostras com concentrações altas, médias e baixas de IGF-I, foram quantificadas utilizando-se kit comercial e os resultados foram comparados com as concentrações obtidas nos métodos in house com ou sem incubação prévia.

0 ensaio com incubação prévia das amostras com o anticorpo apresentou concentrações inferiores (entre 90 a 66\%) as obtidas com o kit comercial (Fig.3A), contudo o comportamento dos ensaios apresentou similaridade e uma correlação de 0,8065 entre os resultados. Já quando foi empregado o método sem incubação prévia, com diluição do anticorpo específico 1:80.000, as concentrações encon-
Quadro 1. Comparativo dos indices de correlação, $\mathbf{r}^{2}$, IC50, SQ e DPRes obtidos após a titulação do anticorpo anti-IGF-I no método sem incubação prévia das amostras com o anticorpo anti-h-IGF-I

\begin{tabular}{cccccc}
\hline $\begin{array}{c}\text { Diluição } \\
\text { Anticorpo }\end{array}$ & Correlação & $\mathrm{r}^{2}$ & $\begin{array}{c}\text { IC50 } \\
(\mathrm{ng} / \mathrm{mL})\end{array}$ & SQ & DP Res \\
\hline $1: 80.000$ & $-0,9264$ & 0,9902 & 240,2 & 0,1763 & 0,0469 \\
$1: 160.000$ & $-0,9661$ & 0,9940 & 195,8 & 0,1433 & 0,0423 \\
$1: 200.000$ & $-0,9809$ & 0,9933 & 209,9 & 0,1329 & 0,0407 \\
$1: 250.000$ & $-0,9910$ & 0,9984 & 207,6 & 0,0025 & 0,0178 \\
$1: 300.000$ & $-0,9877$ & 0,9974 & 145,4 & 0,0032 & 0,0199
\end{tabular}

$\mathrm{r}^{2}=$ coeficiente de regressão, IC50 = concentração capaz de provocar 50\% do efeito máximo, $\mathrm{SQ}=$ soma de quadrados (escala logarítmica), DP Res = desvio padrão dos resíduos (valores absolutos da D.O.)

Quadro 2. Avaliação da sensibilidade analítica após diluições seriadas de amostra de plasma em tampão de ensaio

\begin{tabular}{ccccc}
\hline $\begin{array}{c}\text { Fator de } \\
\text { diluição } \\
\text { da amostra }\end{array}$ & $\begin{array}{c}\text { \% da } \\
\text { dose } \\
\text { total }\end{array}$ & $\begin{array}{c}\text { Valor } \\
\text { esperado* } \\
\text { (ng/mL) }\end{array}$ & $\begin{array}{c}\text { Valor obtido } \\
\text { 土 EPM } \\
(\mathrm{ng} / \mathrm{mL})\end{array}$ & $\begin{array}{c}\text { \% obtida } \\
\text { do valor } \\
\text { esperado }\end{array}$ \\
\hline $1: 2$ & 50 & 173,3 & $146,6 \pm 4,86$ & 42,2 \\
$1: 4$ & 25 & 86,65 & $69,4 \pm 2,68$ & 20 \\
$1: 8$ & 12,5 & 43,32 & $46,8 \pm 3,49$ & 13,5
\end{tabular}

Os dados apresentados são representativos de 2 extrações com 2 quantificações independentes realizadas em quadruplicata. *Concentração determinada pelo kit comercial.

tradas foram mais próximas ao método comercial, principalmente, nas amostras com concentrações de IGF-I elevadas (Fig.3B), e a correlação entre as doses foi de 0,7746.

Em função desses resultados, as amostras foram quantificadas novamente utilizando o protocolo que não realizava incubação previa das amostras, porém utilizando uma diluição maior do anticorpo (1:250.000). Como pode ser observado nas Figuras 4A e 4B, o aumento na diluição aumentou a exatidão do método, sendo esta comprovada pela maior correlação $(r=0,945)$ e pela linha de tendência entre as doses que apresentou $\mathrm{r}^{2}$ de 0,893 .

Como consequência do aumento da exatidão, foi observada uma redução da diferença percentual, uma vez que $78 \%$ das amostras apresentaram diferença percentual inferior a $22 \%$ entre as doses obtidas com a metodologia in house em relação a comercial. 
A metodologia sem incubação prévia e diluição do anticorpo específico de 1:250.000 proporcionou boa precisão, pois os coeficientes de variação intra-ensaio para o controle alto e baixo, calculados após 33 ensaios realizados em 4 etapas com intervalos de 3 dias $(5,8,10$ e 10 ensaios/ dia), foram de $9,05 \pm 4,06 \%$ (com média de $345,8 \mathrm{ng} / \mathrm{mL}$ ) e 10,51 $\pm 4,86 \%$ (com média de $131,6 \mathrm{ng} / \mathrm{mL}$ ), respectivamente. Já os coeficientes de variação inter-ensaio foram de $12,94 \%$ para o controle alto e $20,71 \%$ para o controle baixo.

\section{Limite de quantificação inferior}

Como apresentado no Quadro 2, as concentrações mensuradas pelo ensaio in house apresentaram redução proporcional em função do aumento da diluição da amostra até a razão de 1:8, ou seja, o equivalente a $12,5 \%$ do total de IGF-I presente na amostra $(346,6 \pm 9,19 \mathrm{ng} / \mathrm{mL}$ de IGF-I, mensurado pelo kit comercial). A partir dessa diluição (1:8) a metodologia analítica apresentou início de perda na sensibilidade, sendo por isso estabelecido o limite de detecção próximo a 50ng/mL.
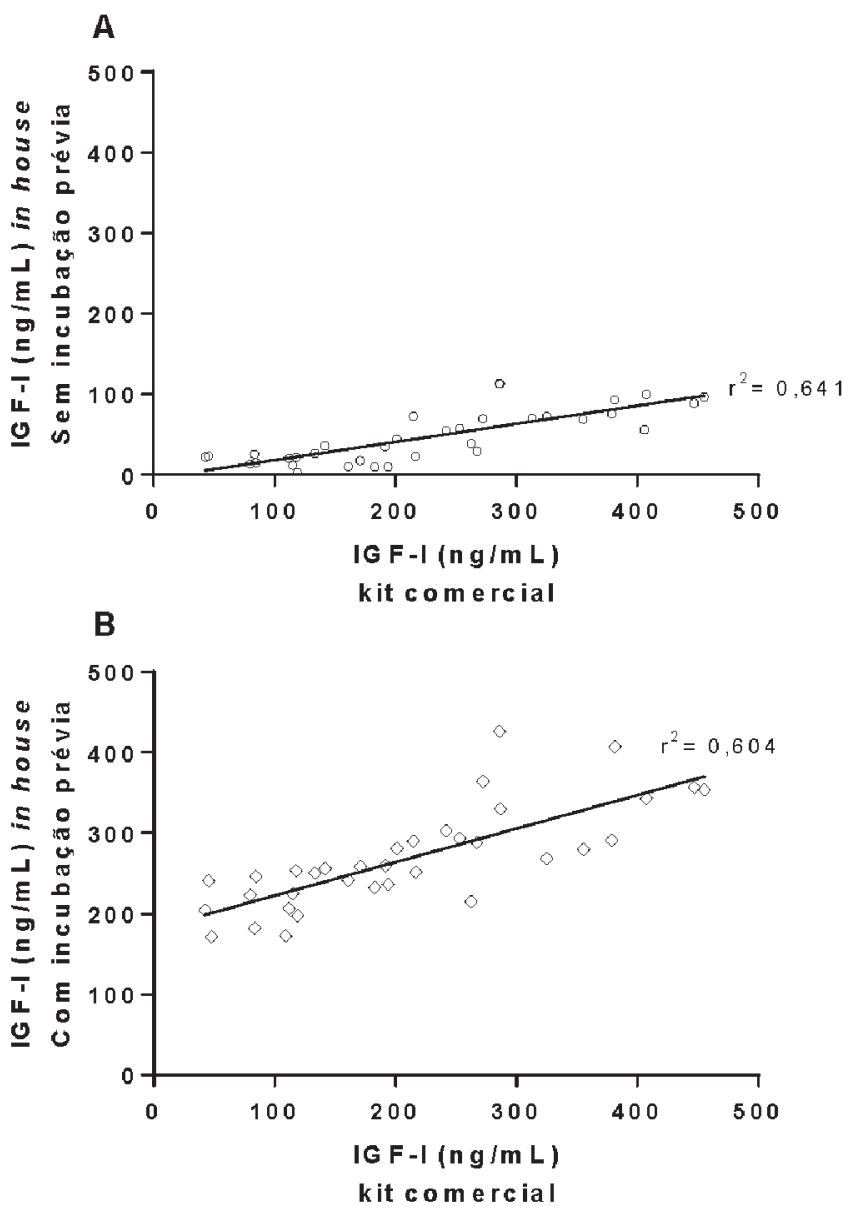

Fig.3. (A) Correlação entre as doses obtidas com o kit comercial e o ensaio in house com incubação prévia ou (B) sem incubação prévia da amostra com anticorpo anti-IGF-I na diluição 1:80.000. As dosagens com o kit foram realizadas em duplicata/amostra e as da metodologia in house em dois ensaios independentes realizados em duplicata/amostra e os resultados apresentados como média \pm EPM.
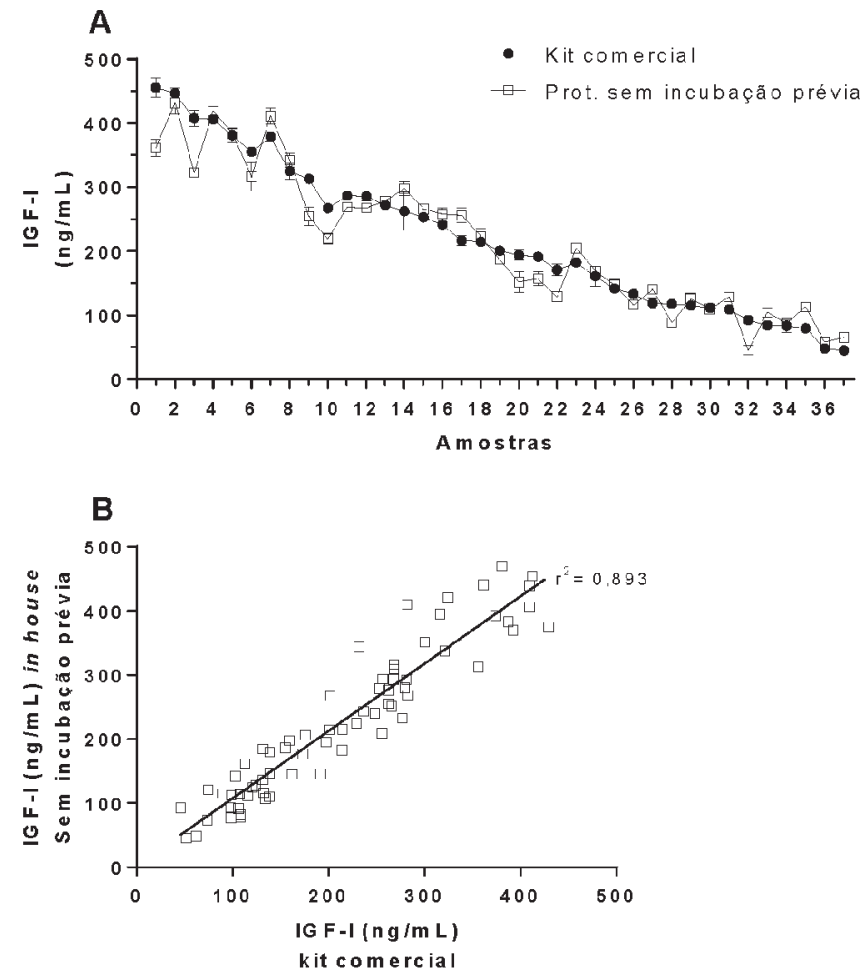

Fig.4. Comparativo das concentrações obtidas com a metodologia comercial e ensaio in house sem incubação prévia da amostra com anticorpo anti-IGF-I na diluição 1:250.000. (A) Amostras organizadas de forma decrescente em função da dose encontrada com o kit comercial. (B) Correlação entre as doses obtidas com o kit e a metodologia sem incubação prévia das amostras com o anticorpo anti-h-IGF-I. As dosagens com o kit foram realizadas em duplicata/amostra e as da metodologia in house após dois ensaios independentes realizados em duplicata/ amostra e os resultados apresentados como média \pm EPM.

\section{Linearidade}

O ensaio in house de quantificação de IGF-I apresentou a variação da D.O. da curva padrão com comportamento não linear, por esse motivo a regressão logística de 4 parâmetros foi aplicada (Fig.5A). Após a transformação das concentrações dos padrões em log de base 10 e a conversão da D.0. em $\% \mathrm{~B} / \mathrm{B}_{0}$ seguida pela aplicação da função logit, os dados passaram a apresentar característica linear (Fig.5B).

No entanto, ao aplicar-se a equação linear para o cálculo das concentrações dos padrões, houve uma maior dispersão dos resíduos em relação a concentração nominal de cada padrão quando comparada com os resultados obtidos com a regressão logística de 4 parâmetros (Fig.5C,D).

\section{DISCUSSÃO}

O método descrito nesse trabalho é pioneiro na quantificação de IGF-I plasmático total utilizando a técnica de duplo anticorpo com o sistema IGF-I-biotina-estreptavidina. Os métodos imunoenzimáticos (ELISA) atualmente disponíveis para quantificação desse hormônio são no sistema sanduíche, que utiliza um anticorpo específico para sensibilização da microplaca e o marcado (especifico para outro epítopo do mesmo antígeno) ligado à peroxidase (horseradish peroxidase, HRP). 

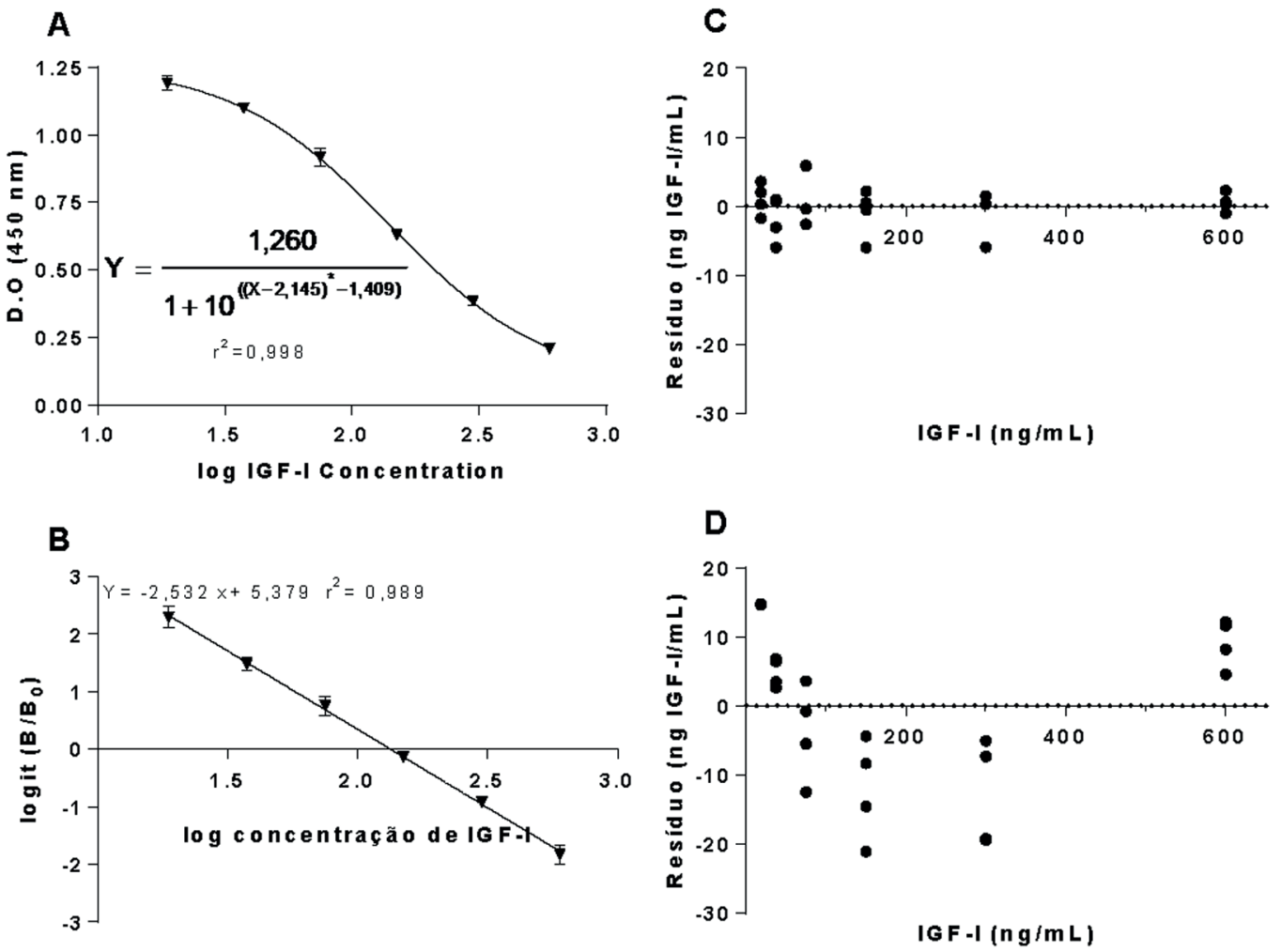

Fig.5 Curvas padrão elaboradas utilizando o protocolo in house sem incubação prévia das amostras com o anticorpo anti-IGF-I na diluição de1:250.000 e análise dos resíduos das doses nominais e das doses calculadas. (A) Regressão logística de 4 parâmetros. (B) Regressão linear após linearização dos dados com função log-logit. (C) Resíduos das doses calculadas pela regressão logistica de 4 parâmetros. (D) Resíduos das doses calculadas pelo metodo log-logit. Os dados, expressos pela média \pm EPM, são representativos de quatro curvas padrão realizados em 3 dias diferentes e em duplicata.

A utilização de um anticorpo secundário (IgG produzidas em cabra contra IgG de coelho) na sensibilização das placas apresenta-se como uma alternativa ao ELISA do tipo sanduíche, uma vez que reduz o coeficiente de variação intra-ensaio e diminui a quantidade de anticorpo específico (Meyer 1986) utilizado no ensaio.

O primeiro passo para o estabelecimento do ELISA de captura consistiu na elaboração de testes de ligação que estimam a melhor concentração do anticorpo secundário, do anticorpo específico e do IGF-I biotinilado.

0 antígeno biotinilado nesse método apresentou boa capacidade de ligação, na maioria das combinações de diluição dos anticorpos testados e nos diferentes períodos de incubação, uma vez que as densidades ópticas ficaram acima de 1,0. Isso pode ser justificado pela possível conjugação de mais de uma molécula de biotina em cada molécula de IGF-I, visto que a fonte de biotina utilizada apresenta elevada afinidade com aminas primárias presentes na lisina, e de acordo com Rinderknecht e Humbel (1977) esse hormônio possui 3 lisinas em sua estrutura.

Ainda considerando os resultados dos testes de ligação, a concentração inicial do anticorpo de captura para elaboração dos testes foi de $1 \mu \mathrm{g}$ de IgG de cabra anti coelho/ poço (anticorpo de captura), além de serem testadas concentrações inferiores $(0,25 ; 0,5$ e $0,75 \mu \mathrm{g}$ /poço). A redução das concentrações do anticorpo de captura não foi um dos fatores limitantes (interferiu na DO final), indicando que o sistema de captação do complexo antígeno-anticorpo não foi afetado.

0 correto estabelecimento da quantidade de anticorpo anti IgG de coelho a ser utilizada para adsorção na microplaca é importante nesse ensaio de captura em fase sólida, pois a inserção de grandes quantidades de anti-IgG pode induzir a formação de camadas sobrepostas com menor estabilidade em função das fracas interações das ligações existentes entre as proteínas dos anticorpos, o que compromete a reprodutibilidade do ensaio (Butler 2000).

Ao avaliarmos a influência das diluições do anticorpo específico e do antígeno conjugado à biotina na densidade óptica, foi possível observar que o maior fator de interferência foi a concentração do IGF-I biotinilado, e com menor influência as diluições do anticorpo específico, utilizamos 0,06ng/poço de IGF-I biotinilado e a diluição 1:80.000 do anticorpo específico.

Após o estabelecimento das proporções dos constituintes principais a serem utilizados nos ensaios, foram elaboradas curvas padrão com diferentes volumes dos padrões $(20,40,60$ e $80 \mu \mathrm{L})$. Para a escolha do volume mais adequado dos padrões e amostras para ser utilizado nos ensaios, os parâmetros considerados foram o índice de correlação entre a densidade óptica e o aumento das concentrações das soluções padrão (r), a confiabilidade da regressão $\left(\mathrm{r}^{2}\right)$, o valor do IC50, a soma dos resíduos e o desvio padrão dos resíduos. 
De acordo com o preconizado pela resolução RE899 (Anvisa 2003), em testes quantitativos para a determinação de princípio ativo em produtos farmacêuticos ou matérias primas (categoria I), os valores de $\mathrm{r}$ e $\mathrm{r}^{2}$ devem ser iguais ou superiores a 0,9 para utilização da curva como padrão de cálculo das concentrações das amostras. Com a utilização de 60 e $80 \mu \mathrm{L}$ os valores desses coeficientes foram superiores a 0,98 .

Os critérios finais para a escolha entre os dois volumes acima citados foram a soma de quadrados (SQ) e o desvio padrão dos resíduos (DPRes), pois estas medidas de dispersão indicam o quanto as D.O. estão distantes da equação traçada (Souza 1998). 0 uso de $60 \mu \mathrm{L}$ dos calibradores apresentou valores inferiores de SQ e DPRes, por esse motivo foi escolhido como volume a ser utilizado. Além disso, dos 11 padrões estabelecidos inicialmente, foram retiradas da curva as concentrações equivalentes a 2,34; 4,68; 9,37; 750 e $1000 \mathrm{ng} / \mathrm{mL}$.

Com os parâmetros básicos do ensaio já determinados, foi realizada a quantificação do IGF-I de 37 amostras utilizando os dois protocolos in house, já descritos, com anticorpo específico na diluição de 1:80.000. 0 método com incubação prévia apresentou doses mais similares às do kit comercial quando comparado com o método sem incubação prévia, todavia em amostras com baixas concentrações de IGF-I houve menor sensibilidade na detecção. Com base nesses resultados, o método com incubação prévia das amostras com o anticorpo específico deixou de ser utilizado e as quantificações foram novamente realizadas, agora utilizando apenas o método sem prévia incubação e com o anticorpo anti-IGF-I diluído para 1:250.000.

0 aumento da diluição do anticorpo específico, além de tornar o ensaio sem incubação prévia mais sensível à detecção de IGF-I, ampliou a exatidão do método sendo obtida uma correlação entre doses de 0,945 e uma diferença percentual menor entre as concentrações apresentadas pelo kit em relação ao método in house. Dessa forma, pode-se dizer que a melhora dos resultados foi consequência de uma associação entre a redução da quantidade de anticorpos específicos disponíveis, aliada a adição simultânea do antígeno marcado e da amostra.

Contudo, a utilização do protocolo sem incubação prévia diverge dos princípios adotados para a quantificação do mesmo hormônio por radioimunoensaio, visto que nas metodologias descritas por Lacau-Mengido et al. (2000), Lalman et al. (2000) e Breier et al. (1991) é realizada uma pré-incubação das amostras com o anticorpo específico para posterior adição do IGF-I marcado com o radioisótopo.

Mesmo com o desenvolvimento de um teste com elevada exatidão, e com uma evidente melhora na sensibilidade, foram realizados testes de paralelismo para comprovação da sensibilidade do método e estabelecimento do limite de quantificação inferior, de acordo com as exigências da resolução publicada pela ANVISA em 2003.

Os testes demonstram que o método para quantificação de IGF-I produziu resultados bem próximos aos teóricos, calculados em função da diluição aplicada antes da extração. Com esse mesmo teste foi possível observar que com diluições superiores a 1:8 $(12,5 \%$ de amostra e $87,5 \%$ de tampão) aplicadas a uma amostra com 346ng de IGF-I/mL os resultados passaram a ser mais distantes da dose calculada. Em virtude disso, foi estabelecido como limite de quantificação inferior a dose de $50 \mathrm{ng} / \mathrm{mL}$, que se encontra bem abaixo das concentrações relatadas na literatura para espécie bovina, que pode variar de 150 a $600 \mathrm{ng} / \mathrm{mL}$ (Cooke et al. 2013, Buratini 2000, Beltran 2007).

Durante as análises de paralelismo também foram avaliados os possíveis erros provocados pela extração das amostras. Em linhas gerais, o IGF-I produzido pelo fígado antes de ser liberado na corrente sanguínea é ligado à proteína transportadora de fatores de crescimento semelhantes à insulina (IGFPBs) com o intuito de facilitar o transporte e aumentar a meia vida do hormônio (Ballard et al. 1989, Blum et al. 1989). Nesse contexto, métodos que objetivam a quantificação de IGF-I total, e não apenas da fração livre, exigem um processo prévio de desligamento do hormônio das IGFPBs.

A extração consiste na indução do desligamento pela acidificação da amostra com posterior neutralização, sendo amplamente difundidos os métodos que utilizam etanol-ácido (Breier et al. 1991) e o tampão glicina acidificado (Lalman et al. 2000). No presente estudo, a extração foi realizada utilizando o tampão glicina $1 \mathrm{M}$ acidificado seguido da neutralização com $\mathrm{NaOH}$, uma vez que esse método não exerce efeito negativo sobre a interação do antígeno com o anticorpo, induz eficientemente o desligamento do hormônio de sua proteína transportadora, além de não utilizar etanol, já que o uso de álcoois (principalmente com dois ou mais carbonos) pode alterar a conformação proteica dificultando a interação com o anticorpo nos sistemas imunoenzimáticos (Von Maltzan \& Pruet 2011).

Dentre as inúmeras variações disponíveis em ensaios imunoenzimáticos, o ELISA do tipo sanduíche é reconhecido como o de maior especificidade, pois o uso de dois anticorpos específicos (um adsorvido a fase sólida e o outro ligado a HRP) amplia a especificidade na detecção do antígeno de interesse (Gan \& Patel 2013). Comparando-se as doses do método in house de competição em relação ao kit, a proximidade encontrada entre as doses indica que não houve perda da especificidade mesmo utilizando apenas um anticorpo especifico policlonal nos ensaios.

De acordo com a RE899 (Anvisa 2003), outro parâmetro que deve ser considerado durante a validação de ensaios quantitativos é a linearidade, ou seja, a variação nas concentrações do analito deve produzir resposta linear e caso essa não exista deve se realizar transformação matemática para que seja atingida. No entanto, uma das características de ensaios imunológicos é a ausência de resposta linear e uma das transformações mais utilizadas para a linearização de dados é a Log-Logit (Deshpande 1996).

Ao aplicar essa transformação nas D.0. da curva, os dados passaram a apresentar linearidade, ainda assim, foi realizada uma análise da dispersão dos resíduos das doses calculadas pela equação linearizada e as concentrações nominais dos padrões utilizados na curva de calibração, e posteriormente o mesmo foi realizado utilizando um método não linear (regressão logística de 4 parâmetros).

A dispersão dos resíduos quando aplicada a linearização 
apresentou maior heterogeneidade de distribuição, principalmente nos extremos da curva padrão, sendo observado o oposto com a regressão logística. Essa heterogeneidade de distribuição indica que a equação não intercepta corretamente os pontos nos extremos da curva, provocando alteração na inclinação da equação e aumentando o nível de imprecisão. Sendo assim, o modelo mais adequado para conversão da densidade óptica das amostras para doses foi o não linear, mesmo apresentando característica não desejável pela resolução da ANVISA, a norma do INMETRO DOQ-CGCRE-008 (Inmetro 2007) permite a utilização desse tipo de modelo para métodos analíticos que apresentam resposta não linear.

\section{CONCLUSÃO}

A metodologia imunoenzimática para quantificação de IGF-I total utilizando o sistema de amplificação biotina-estreptavidina peroxidase em um ensaio competitivo está estabelecida e apresenta-se como uma ferramenta útil para estudos que visam o monitoramento das concentrações de IGF-I.

\section{REFERÊNCIAS}

Andoh T. 2005. Development of non-radioisotopic immunoassay systems for measuring flounder IGF-I. Zool. Sci. 22:1023-1030.

Anvisa 2003. Portaria nำ238. Resolução - RE no899, 29 mai. 2003, Agência Nacional de Vigilância Sanitária. Disponível em <http;//www.anvisa. gov.br/legis/resol/2003/re/899_03re.htm> Acesso em 28 nov. 2015.

Ballard J., Baxter R., Binoux M., Clemmons D., Drop S., Hall K., Hintz R., Rechler M., Rutanen E. \& Schwander J. 1989. On the nomenclature of the IGF binding proteins. Acta Endocrinol. 121:751-752.

Beltran M.P. 2007. Possíveis efeitos da leptina e IGF-I plasmáticos sobre a puberdade e a precocidade sexual de novilhas Nelore (Bos taurus indicus). Tese de Doutorado, Faculdade de Medicina Veterinária e Zootecnia, Universidade de São Paulo, São Paulo, SP.

Blum W.F., Jenne E.W., Reppin F., Kietzmann K., Ranke M.B. \& Bierich J.R. 1989. Insulin-like growth factor I (IGF-I)-binding protein complex is a better mitogen than free IGF-I. Endocrinology 125:766-772.

Breier B.H., Gallaher B.W. \& Gluckman P.D. 1991. Radioimmunoassay for insulin-growth factor-I: solutions to some potential problems and pitfalls. J. Endocrinol. 128:347-357.

Buratini Jr J., Price C.A., Visintin J.A. \& Bó G.A. 2000. Effects of dominant follicle aspiration and treatment with recombinant bovine somatotropin (BST) on ovarian follicular development in Nelore (Bos indicus) heifers. Theriogenology 54:421-431.

Butler J.E. 2000. Solid supports in enzyme-linked immunosorbent assay and other solid-phase immunoassays. Methods 22:4-23.

Cooke R.F.., Bohnert D.W., Francisco C.L., Marques R.S., Mueller C.J. \& Keisler D.H. 2013. Effects of bovine somatotropin administration on growth, physiological, and reproductive responses of replacement beef heifers. J. Anim. Sci. 91:2894-2901.

Deshpande S.S. 1996. Enzyme Immunoassays: from concept to product development. Chapman and Hall, New York. 464p.

Gan S.D. \& Patel D.R. 2013. Enzyme immunoassay and enzyme-linked immunosorbent assay. J. Invest. Dermatol. 133:1-3.

Garcia M.R., Amstalden M., Williams S.W., Stanko R.L., Morrison C.D., Keisler D.H., Nizielski S.E. \& Williams G.L. 2002. Serum leptin and its adipose gene expression during pubertal development, the estrous cycle, and different seasons in cattle. J. Anim. Sci. 60:2158-2167.

Hiney J.K., Srivastava V.K. \& Les Dees W. 2010. Insulin-like growth factor-1 stimulation of hypothalamic KiSS-1 gene expression is mediated by Akt: effect of alcohol. Neuroscience 166:625-632.

Inmetro 2007. Orientação sobre validação de métodos de ensaios químicos, Instituto Nacional de Metrologia, Qualidade e Tecnologia. Disponível em <http://www.inmetro.gov.br/credenciamento/laboratórios/ calibEnsaios.asp> Acesso em 20 dez. 2015.

Ketelslegers J.M., Maiter D., Maes M., Underwood L.E. \& Thissen J.P. 1995. Nutricional regulation of insulin-like growth factor I. Metabolism 44:50-57.

Lacau-Mengido I.M., Mejia M.E., Díaz-Torga G.S., Gonzalez Iglesias A., Formía N., Libertun C. \& Becú-Villalobos C. 2000. Endocrine studies in ivermectin-treated heifers from birth to puberty. J. Anim. Sci. 78:817-824.

Lalman D.L., Williams J.E., Hess B.W., Thomas M.G. \& Keisler D.H. 2000. Effect of dietary energy on milk production and metabolic hormones in thin primiparous beef heifers. J. Anim. Sci. 78:530-538.

Meyer H.H.D. 1986. Possibilities to improve enzyme immunoassay (EIA) techniques and their application in animal production, p.255-262. In: Ibid. (Ed.), Proceedings of International Symposium on the Use of Nuclear Techniques in Studies of Animal Production and Health in Different Environments. IAEA, Vienna.

Piechotta M., Holzhausen L., Araujo M.G., Heppelmann M., Sipka A., Pfarrer C., Schuberth H.J. \& Bollwein H. 2014. Antepartal insulin-like growth factor concentrations indicating differences in the metabolic adaptative capacity of dairy cows. J. Vet. Sci. 15:343-352.

Radcliff R.P., VandeHaar M.J., Kobayashi Y., Sharma B.K., Tucker H.A. \& Lucy M.C. 2004. Effect of dietary energy and somatotropin on components of the somatotropic axis in Holstein heifers. J. Dairy Sci. 87:1229-1235.

Rinderknecht E. \& Humbel R.E. 1977. The amino acid sequence of human insulin-like growth factor I and its structural homology with proinsulin. J. Biol. Chem. 263:2769-2776.

Simpson R.B., Armstrong J.D., Harvey R.W., Miller D.C., Heimer E.P. \& Campbell R.M. 1991. Effect of active immunization against growth hormone-releasing factor on growth and onset of puberty in beef heifers. J. Anim. Sci. 69:4914-4924.

Souza G. 1998. Introdução aos modelos de regressão linear e não-linear. Embrapa-SPI, Brasília, DF.

Von Maltzan K. \& Pruett S.B. 2011. ELISA assays and alcohol: increasing carbon chain length ca interfere with detection of cytocines. Alcohol 45:1-9.

Yakar S., Liu J.L., Stannard B., Butler A., Accili D., Sauer B. \& Leroith D. 1999. Normal growth and development in the absence of hepatic insulin-like growth factor I. Proc. Nat. Acad. Sci. USA 96:7324-7329. 